\title{
1 Determining the effects of duration and recency of exposure to environmental enrichment
}

$5 \quad{ }^{a}$ Department of Ecology, Environment and Plant Sciences, Stockholm University , 10691

6 Stockholm, Sweden

$7 \quad{ }^{b}$ Department of Biology, University of Bergen, N-5020 Bergen, Norway

$8{ }^{\mathrm{c}}$ Center for Brain, Behavior, and Cognition, Department of Ecosystem Science \& Management

9 and Department of Biology, Pennsylvania State University, University Park, PA 16802, USA

$11 *$ Author for correspondence

12 Address: Department of Ecology, Environment and Plant Sciences, Stockholm University, 10691

13 Stockholm, Sweden. Telephone: $+46(0) 7046012$ 65, Fax: +46(0)8 158 417, e-mail:

14 ida.ahlbeck@su.se 


\section{Abstract}

20 Experience can help animals adapt their behaviour to fit the environment or conditions that they

21 find themselves in. Understanding how and when experience affects behaviour is important for

22 the animals we rear in captivity. This is particularly true when we rear animals with the intent of

23 releasing them into the wild as part of population rehabilitation and conservation efforts. We

24 investigated how exposure to a changing, more complex environment promotes behavioural

25 development in juvenile trout. Four groups of fish were compared; (i) fish that were maintained

26 without enrichment, (ii) fish that were exposed to an early period of enrichment, but were then

27 returned to a plain environment, (iii) fish that were maintained in plain conditions, but were then

28 exposed to enrichment towards the end of the rearing phase, (iv) a group that were kept in

29 enriched conditions throughout the 12 week rearing period. We then assessed fish anxiety levels,

30 their spatial learning ability, and the capacity of the fish to find their way through a barrier where

31 different routes were presented across 4 different trials. Fish that experienced enriched conditions

32 for the longest duration had superior spatial learning abilities, and they were better at finding the

33 correct route to get past the barrier than fish from the remaining three treatments. Positive effects

34 on behaviour were, however, also found in the fish that only experienced enrichment in the last

35 part of the rearing period, compared to the control, or fish exposed to early enrichment. No effect

36 of enrichment were found on levels of anxiety in any of the groups.

38 Keywords: Enrichment, behavioural development, behavioural flexibility, learning, captive

39 rearing

40

41 


\section{$42 \quad 1$. Introduction}

43 Understanding how the environment fine-tunes and shapes behavior is particularly important for

44 those working in the area of captive rearing and release for population rehabilitation. Establishing

45 appropriate ways to rear animals so that they have the capacity to survive and thrive in a real

46 world environment remains a central goal of many applied research programs (Shier and Owings,

47 2006; Salvanes and Braithwaite 2006; Urbanek et al. 2010). Experience during early life can play

48 a significant role in the development of an animal's behavioural phenotype. However the

49 relatively unchanging nature of the captive environment can lead to animals with behavioural

50 deficits and diminished behavioural flexibility (Olla et al. 1994; Brown et al. 2003). The addition

51 of environmental enrichment, or the experience of variation within the environment has been

52 found to promote increased behavioural flexibility and improve aspects associated with cognition

53 (Leggio et al. 2005; Harburger et al. 2007; Strand et al. 2010; Salvanes et al. 2013). As such,

54 there is now growing interest in the effects of adding environmental enrichment and variability

55 into the captive environments in which animals are reared for later release (Rabin 2003;

56 Braithwaite and Salvanes 2005; Seddon et al. 2007).

58 Although practices in terrestrial systems are extensively more developed than those in aquatic

59 systems (Brown and Day 2002), fisheries biology is a field that is actively exploring ways of

60 rearing animals that behave in ways that smooth the transition from captivity to life in the wild

61 (Heenan et al. 2009; Brockmark et al. 2010). Restocking in an attempt to restore or maintain

62 heavily exploited fish populations is a widespread management practice (Brown and Laland

63 2001). However, survival of hatchery fish is typically lower than for wild fish of the same size or

64 age class. The mortality levels immediately following release can be substantial and there is little 
65 evidence that released fish survive long enough to effectively rehabilitate the struggling

66 populations (Hilborn 1998, Salvanes and Braithwaite 2006).

68 From a stocking perspective, there appear to be benefits of rearing fish in more complex

69 environments than the standard hatchery provide (Näslund and Johnsson 2014). However, despite

70 this knowledge, enrichment is seldom used in hatcheries (Näslund et al. 2012, Näslund et al.

71 2013, Johnsson et al. 2014). Rearing fish with enrichment is more labour intensive than using

72 barren tanks because enrichment makes it more difficult to clean, and there is concern that feed

73 and waste may accumulate which might compromise the health of the animals within these

74 systems (Braithwaite and Salvanes 2010). The addition of enrichment items into the hatchery

75 environment may, however, be a more attractive prospect if the fish only needed a restricted

76 period of exposure to the enrichment (Brown et al 2003).

78 In this study we investigate how the duration and recency of exposure to structural environmental

79 enrichment affects the behavioural development in rainbow trout (Oncorhynchus mykiss), a

80 commonly stocked species. Fish were exposed to three separate enrichment treatments differing

81 in timing (early or late in the experiment) and duration (five or twelve weeks). The fish were then

82 behaviourally screened, comparing three behaviours that are known to be positively influenced by

83 enrichment (Salvanes et al. 2007, Spence et al. 2011, Salvanes et al. 2013); specifically we

84 compared anxiety levels in a novel environment, spatial learning ability in a four armed maze and

85 the ability of the fish to find novel paths to gain access to food (to assess behavioural flexibility).

86 We hypothesized that the effects of enrichment would depend upon how long the fish were able

87 to experience the enrichment, thus fish that had the longest exposure to enrichment would show

88 the greatest benefits in terms of reduced anxiety and increased learning and flexibility. If,

89 however, the effects depend on how recently the fish were exposed to enrichment, we would 
90 expect that fish most recently exposed to the enrichment would outperform those that had no

91 enrichment or that only experienced enrichment at the start of the rearing period only.

\section{2. Material and Methods}

\section{$93 \quad 2.1$ Fish and treatments}

94 Four groups of approximately 50 rainbow trout (Oncorhynchus mykiss) obtained from a local

95 hatchery at 5 months of age were randomly distributed across 4 opaque, flow-through holding

96 tanks $(60 \times 60 \times 95 \mathrm{~cm})$. The fish were fed once per day with commercially produced fish pellets,

97 and were kept on a 12 hour light:dark schedule at a water temperature of $10^{\circ} \mathrm{C}$. After one month

98 of acclimation, four groups were established for the experiment, with four replicate treatment

99 tanks $(90 \times 45 \times 30 \mathrm{~cm})$ in each of the groups and 10 fish in each tank $(\mathrm{n}=40$ per treatment $)$

100 randomly selected from the holding tanks. Enrichment, when provided, consisted of fine grain

101 gravel, upturned, black plastic pots $(10 \mathrm{~cm}$ in diameter) to create areas of shelter, plastic plants

102 (12-30 cm tall) and novel objects (plastic plants of different colour, Ping-Pong balls, green bottle

103 tops ( $3 \mathrm{~cm}$ diameter), grey pvc-pipes $(3 \mathrm{~cm}$ in diameter). When enrichment was not available the

104 tank contained only a filter and an airstone.

105 Group (i) fish experienced enrichment throughout the 12 week rearing phase of the experiment

106 (12 full weeks - Full), Group (ii) were exposed to enrichment continuously for 5 weeks at the

107 start of the experiment and then returned to regular holding tanks ( 5 weeks early - Early), Group

108 (iii) were exposed to enrichment for the last 5 weeks of the experiment ( 5 weeks late - Late), and

109 Group (iv), the control fish, were maintained for 3 months in treatment tanks without enrichment

110 (Control). One complete control replicate tank had to be terminated prematurely owing to a

111 fungal infection, none of these fish took part in the behavioural trials, hence there were only 30

112 individuals tested from the control groups. In addition, four other fish were lost in different tanks

113 (1 Control, 2 Early and 1 Full) again these losses occurred prior to the behavioural assays. At the 
114 end of the experiment, the fish were euthanized and length measurements (standard length) were

115 taken to compare the sizes across the treatments.

116

\section{$117 \quad 2.2$ Behavioural assays}

118 Once the fish reached 9 months of age behavioural screening began. Anxiety, flexibility in habitat

119 use and spatial learning were assessed. The same fish were used in the anxiety and the flexibility

120 trials $(n=76)$, because these two assays were not expected to interfere with each other owing to

121 the very different nature of the tests. New fish, however, were used for the spatial learning task

$122(\mathrm{n}=71)$. Three days before the behavioural assays began, the fish were anaesthetised with buffered

123 Tricaine-S (MS-222, Sigma) and marked to permit individual identification with $3 \mathrm{~mm}$ long UV-

124 florescent elastomer tags under the skin of the lower jaw using a hypodermic syringe.

\section{$125 \quad$ 2.2.1 Assessing flexibility}

126 To assess the flexibility in habitat use, a series of 4 tasks were given to the fish over 4 consecutive 127 days (modified from Reader and Laland 2000). For each task, the fish had to find a route from

128 one side of a tank to the other where they were able to access a feeder (Fig. 1). At the start of each

129 trial, a fish was placed in one half of a tank with a dividing wall that had a single exit hole

130 providing access to the other side of the tank. On each day of the test the exit was placed in a

131 different position. Individual fish were transferred to the test tank and given a 30 minute settling

132 period with an opaque partition blocking access to the partition wall. Trials began when the

133 partition was removed, and the latency to enter the exit hole was noted. For tests 1 and 2, the exit

134 was simply a hole on either the left or the right, and the trout were given 15 minutes to find it. For

135 tests 3 and 4, the fish had to enter a tube to access the exit hole, as this was a more difficult task

136 the fish were given 20 minute trials. The number of fish that found the route to the feeder was

137 noted. These trials were run with n=20, 20, 21 and 15 for the Early, Late, Full and Control fish

138 respectively. 


\section{$140 \quad$ 2.2.2 Assessing spatial cognition}

141 Spatial cognition, involving perceiving and interpreting spatial cues, as well as storing and

142 retrieving this information (modified from Brockmark et al. 2010), was assessed using a maze

143 with a central compartment $(20 \times 30 \times 14 \mathrm{~cm})$ and four arms at each corner leading to doors (Fig. 2)

144 and contained nothing else. Three of the doors were blocked with transparent Perspex that created

145 dead-ends, while one exit remained open. The whole maze was brightly lit and had a light grey

146 interior. The maze was placed in a larger test tank $(90 \times 45 \times 30 \mathrm{~cm})$ containing a conspecific to

147 motivate the test fish to exit the maze. Individual fish were tested once a day for 5 minutes, or

148 until they found the maze exit. These trials were run for 13 consecutive days with $n=20,18,20$

149 and 15 for the Early, Late, Full and Control fish respectively. The number of false exits entered

150 (errors) was recorded as the number of mistakes made, and the time it took to exit the maze was

151 also noted.

152

\section{$153 \quad$ 2.2.3 Assessing anxiety}

154 A novel tank diving test that is a three dimension version of the open field test, was used to

155 measure anxiety (Cachat et al. 2010). Time spent in the center of the area and number of times

156 fish left the tank floor to explore the upper water layers was taken as evidence of less anxious

157 fish. The test tank measured $45 \times 75 \times 30 \mathrm{~cm}$, with a water depth of $36 \mathrm{~cm}$ and contained nothing

158 else. The tank was covered with black plastic on three sides. Individual fish were tested by

159 releasing them from a dip net into the upper part of the tank in the same position to minimize

160 bias. Across the treatments Early, Late, Full and Control we tested 21, 20, 20 and 15 fish

161 respectively. Each fish was allowed to explore the tank for 5 minutes. The movement and

162 behaviour of the fish was filmed from a camera positioned in front of the uncovered tank side.

163 After the trials, the following were obtained from the video recordings; time spent motionless on 
164 the bottom and horizontal and vertical position of the fish. During video analysis the tank was

165 divided into three vertical zones (top, middle and bottom, each $12 \mathrm{~cm}$ deep) and the bottom

166 vertical zone was further horizontally divided into middle and edge (edge reaching $12 \mathrm{~cm}$ from

167 each tank wall). Every 15 seconds the horizontal zone in which the fish was observed was noted

168 and the number of entries into any of the middle or top vertical zones and time spent immobile

169 were continuously noted. More anxious fish are expected to spend more time motionless and

170 around the edges of the tank and make fewer entries into higher water layers (see Cachat et al.

171 2010).

172

\section{$173 \quad 2.3$ Ethical note}

174 All behavioural screening was non-invasive. Individual fish were separated from the rest of their

175 group for the duration of the tests only. If a fish showed any sign of illness or injury it was

176 removed from experimental set up and euthanized with an overdose of buffered Tricane-S to

177 prevent suffering. One of the control groups (10 fish) were prematurely eliminated from the

178 experiment due to three fish developing fungal infections. The infected fish were euthanized with

179 an overdose of buffered Tricane-S to prevent suffering and the entire group was excluded from

180 the experiment as the social environment of the group had been changed, possibly affecting the

181 behavioural development. Elastomer tagging was performed under anaesthesia and fish were

182 allowed to recover for three days before screening. The long term effects of tagging such as pain,

183 discomfort from anaesthesia or handling stress were considered minimal. There was no mortality

184 associated to tagging, anaesthesia, handling or behavioural screening. When the behavioural

185 screening was finished the fish were euthanized using an overdose of buffered Tricaine-S. As the

186 fish were from a hatchery it was not possible to release them into local streams, hence the need

187 for euthanasia after the completion of the experiment. All of the experiments were approved by

188 the Penn State IACUC Committee, Protocol \# 45265. 


\subsection{Data analysis}

191 The data were analysed in StatView 4, R 3.1.1 (R Development Core Team, http://www.r-

192 project.org) and Stata 13. Standard length data were compared in a one-way ANOVA with fish

193 length as the dependent variable. In the flexibility tests the time to find the hole and reach the

194 other side of the tank containing the feeder was analysed using survival analysis with Cox

195 regression, where also censored observations are taken into account, followed by pairwise

196 comparisons between treatments. Time was used as the dependent variable and treatment and task

197 as the independent variables (factors). Based on the number of fish that completed the task, the

198 probability of the fish finding their way to the other side of the tank was analysed using a mixed

199 effect logistic regression model, with probability to exit $(0 / 1)$ as the response variable and

200 treatment and task number (1-4) as explanatory factors.

202 In the spatial learning assay, the number of fish that found the true exit was compared with a Chi

203 Square-test on trial 1 and trial 13. Based on the number of false exits the fish entered before

204 exiting the maze the average probability to exit the maze without making any mistakes was

205 calculated using a geometrical probability model $(\operatorname{logit}(\mathrm{p})=\mathrm{a}+\mathrm{b} *$ trial $)$. The model estimation was

206 performed in Stata 13 with a maximum likelihood procedure where also censored observations

207 are taken into account. To compare the exit-probability between treatments, the average $\mathrm{p}$ at trial

2081 and trial 13 was compared using ANCOVA on logit-transformed $\mathrm{p}$ in order to fulfil normality,

209 with length as a co-variate, followed by pairwise test. To compare the time it took for fish from

210 the different treatments to exit the maze data was analysed using survival analysis with a Cox

211 regression shared frailty model, where all observations from one specific fish shares the same

212 frailty, corresponding to a random effect model at fish level. Explanatory variables are treatment, 213 trial and length. 
215 In the anxiety test the time spent motionless on the bottom of the tank and position on the tank

216 floor (number of middle or edge registrations) were analysed using an ANOVA and Kruskal-

217 Wallis test respectively. The proportion of fish that moved between the bottom of the tank and

218 any of the surface water layers was compared with a Chi Square-test and the number of entries

219 into higher water layers of the tank was analysed using Welch's test.

220

221 3. Results

\section{$222 \quad 3.1$ Fish Size}

223 All fish had their length measured when the behavioural trials were concluded. Differences in

224 mean length was analysed seperately for the flexibility and anxiety test and for the maze tests as

225 two different groups of fish were used in these tests. Mean lengths \pm SE for the flexibility and

226 anxiety tests were $14.3 \pm 0.4 \mathrm{~cm}$ for Early, $11.5 \pm 0.3 \mathrm{~cm}$ for Late, $15.4 \pm 0.3 \mathrm{~cm}$ for Full and

$22715.1 \pm 0.5 \mathrm{~cm}$ for Control. For the maze test the mean lengths $\pm S E$ were $13.6 \pm 0.3 \mathrm{~cm}$ for Early,

$22814.4 \pm 0.4 \mathrm{~cm}$ for Late, $14.6 \pm 0.3 \mathrm{~cm}$ for Full and $15.0 \pm 0.5 \mathrm{~cm}$ for Control. The Early fish were

229 significantly smaller than the other treatments $\left(\mathrm{F}_{3,144}=3.84, \mathrm{p}=0.01\right)$ in the maze group, hence

230 length was incorporated into the maze analysis.

\section{$232 \quad 3.2$ Flexibility}

233 Based on the number of fish that completed the task the probability that a fish found the exit hole

234 and moved to the other half of the test tank was consistently higher for the Full fish, followed by

235 the Late treatment, the Early treatment and then the Control fish (Fig. 3), with a significant

236 treatment effect (mixed effect logistic regression, Wald $\mathrm{Chi}^{2}=37.67, \mathrm{p}<0.03$ ). Post-hoc tests

237 revealed that there were differences between Full and Early treatments (Fisher's LSD, p=0.029) 
238 and between Full and Control fish (Fisher's LSD, $\mathrm{p}=0.015$ ). The Full fish were also faster to find

239 the exit hole to enter the side of the tank with the feeder than the Control fish (Cox regression

240 with pairwise comparisons, Full vs. Control $\mathrm{p}=0.01$ ).

\section{3. Spatial cognition}

243 There was no difference between treatments in the number of fish that managed to exit the maze

244 on either trial $1(\mathrm{Chi} 2=1.967, \mathrm{df}=3, \mathrm{p}=0.579)$ or trial $13(\mathrm{Chi} 2=3.098, \mathrm{df}=3, \mathrm{p}=0.377)$. However,

245 there was a significant difference between treatments in the probability to exit the maze without

246 making any mistakes (trial $1: \mathrm{F}_{3,68}=4.79, \mathrm{p}=0.004$, trial 13: $\mathrm{F}_{3,68}=2.88, \mathrm{p}=0.042$ ). The Full fish had

247 higher mean probability to exit the maze without mistakes than Early and Control fish (Fig.4) on

248 both trial 1 (Fisher's LSD, Full vs. Early p=0,003, Full vs. Control p=0.018, ) and trial 13 (Fisher's

249 LSD, Full vs. Early $\mathrm{p}=0.028$, Control vs. Full $\mathrm{p}=0.019$ ). Late fish had higher mean probability to

250 exit the maze without mistakes than Early and Control fish on trial 1 (Fisher's LSD, Late vs. Early

$251 \mathrm{~F}=\mathrm{p}=0.008$, Late vs. Control $\mathrm{p}=0.032$ ). There was no effect of length on probability to exit

252 without mistakes (trial 1: $\mathrm{F}_{3,68}=2.77, \mathrm{p}=0.101$, trial 13: $\mathrm{F}_{3,68}=1.40, \mathrm{p}=0.241$ ). Fish significantly

253 improved their time to exit across trials (Wald Chi2 $=136.24, \mathrm{p}<0.001$, Fig. 5) and the Full and

254 Late fish were also generally faster to exit the maze than the Control fish (Wald Chi2 $=136.24$,

255 Full vs. Control $\mathrm{p}=0.048$, Late vs. Control $\mathrm{p}=0.014)$. Length did not have a significant effect on

256 time to exit (Wald Chi2=136.24, $\mathrm{p}=0.175$ ).

\section{$258 \quad 3.4$ Anxiety assay}

259 Anxiety was not affected by timing or duration of enrichment. There were no treatment

260 differences in how long the fish froze, where they were positioned in the tank and how much they

261 used the middle vertical part of the water column (Table 1). Only nine fish in total entered the

262 upper most water layer hindering statistical analysis. 


\section{4. Discussion}

265 Our results support earlier observations that exposing captive animals to physical enrichment

266 positively affects behavioural development (Hunter et al., 2002; Kempermann et al., 2002; Bredy

267 et al., 2003; Rabin, 2003; Braithwaite and Salvanes, 2005; Salvanes et al., 2013; Näslund et al.,

268 2014). However, our results further refine these earlier observations by showing that timing and

269 duration that the animals experience the enrichment can affect the strength of the response.

270 Exposing juvenile rainbow trout to enrichment for three consecutive months produced fish that

271 showed the most improvement in terms of their flexibility and in their learning ability, however

272 we found no effect on anxiety-related behaviours. The next most competent group were the fish

273 that had most recently experienced the enrichment, whereas the group that experienced

274 enrichment in the first part of the experiment, but then returned to standard housing, behaved

275 more similar to the control fish that never experienced any form of enrichment. Together, these

276 results show that both the duration and the recency of which the fish are exposed to enrichment

277 matter for their cognitive ability.

278

279 Being able to find alternative ways of tackling a problem (Giraldeau et al., 1994; Reader and

280 MacDonald, 2003) likely improve survival in changeable, real-world environments (Salvanes and

281 Braithwaite, 2006; Näslund et al., 2014; Johnson et al., 2014). Fish reared in an enriched hatchery

282 environment have previously been shown to have a more context dependant shoaling behaviour

283 (Salvanes et al., 2007) and shelter-seeking behaviour (Näslund et al., 2013). Physical enrichment

284 further seems to improve flexibility of feeding behaviour as seen in the ability to rapidly switch to

285 a new food source (Braithwaite and Salvanes, 2005). We tested this capacity to flexibly utilize the

286 environment by determining how quickly fish could find their way into a part of the tank that

287 contained a food reward. The first two tests were designed to be relatively simple for the fish,

288 whereas the third and fourth tests were more difficult (Reader \& Laland 2000). For each test, the 
289 fish exposed to the enrichment for the longest, the Full group, were consistently better at solving 290 these tasks. This group were not only faster at finding their way into the rewarded compartment, 291 but the probability of a fish completing the tasks was also highest in this group. The proportion

292 of fish that managed to find the exit decreased considerably across all treatments in the third and

293 fourth assay when the fish now had to swim into and then orient themselves correctly within an

294 opaque, dark tube which increased the difficulty of finding the way through to the other side of

295 the tank (Reader \& Laland 2000). The Full fish stand out in terms of both the speed with which

296 they solved this problem and in terms of how many of the fish were able to reach the food reward

297 successfully. The next best explorers were the group that had the enrichment most recently (the

298 Late group). So both duration and recency effects appear to help the fish in terms of developing

299 flexible behavioural responses.

300

301 As almost all animals need to find their way around and learn about their environment, tests of

302 spatial learning can provide useful insight into an individual's learning and memory ability

303 (Healy 1998). Spatial learning involves perceiving and interpreting spatial cues, as well as storing

304 this information, and being able to retrieve the information to follow a specific route or find a

305 location (Brown et al. 2008). Fish have shown increased learning abilities from environmental

306 enrichment in a number of different foraging and spatial learning tasks (Spence et al., 2011;

307 Braithwaite and Salvanes, 2005; Rodewald et al., 2011; Strand et al., 2010). For example,

308 Atlantic salmon (Salmo salar) from enriched conditions were significantly faster to learn the

309 correct exit in a maze, they made fewer mistakes and were faster to leave the maze, compared to

310 fish from plain environments (Salvanes et al., 2013). The maze task we used to assess learning

311 was relatively simple (Grassie et al. 2013), but the increasing probability to find the exit without

312 entering any false exits and the decreased time it took to do so indicates learning, and there were

313 clear differences in the ability to perform this task across the different treatment groups. Both the

314 Full and the Late fish were faster to exit the maze than Control fish, but time to exit could be 
315 affected by motivation and so may not necessarily a reliable indicator of learning. However, the

316 fact that this faster performance was also accompanied by more accurate choices is a stronger

317 indication that both the Full and the Late groups had superior learning and memory skills than

318 either of the Early and Control fish. At five months of age major selection has probably already

319 occurred in wild salmonids as early life stage mortality in the wild is very high (McNeil, 1991);

320 therefore there are likely critical periods for development and learning occurring before this age.

321 However, the present results indicate that learning abilities can still be manipulated after this

322 period, when fish are slightly older and less vulnerable to potential negative effects associated

323 with the structural enrichment, such as waste accumulation.

325 The novel tank diving test has previously been used to gauge levels of anxiety by testing how fish

326 respond to being isolated in a completely new environment (Cachat et al., 2010; Maximino et al.,

327 2010). Typically, fish dive to the bottom of the tank and remain there until they become

328 sufficiently comfortable to start exploring their surroundings. Fish that are less anxious tend to

329 move and explore the tank and swim up into the different parts of the water column earlier than

330 other fish. This assay is rather like a 3-dimensional version of the 2-dimensional open field arena

331 test where animals with lower levels of anxiety move away from the edges and into the middle

332 more quickly (Simon et al., 1994; Harris et al., 2009). Anxiety has previously been shown to

333 decrease in fish from environmentally enriched environments. Braithwaite and Salvanes (2005)

334 showed that cod from standard hatchery environment had significantly higher latency to enter a

335 new area with a stimulus fish compared to fish reared in an enriched environment, indicating that

336 enrichment promotes boldness. They further found that experience with a variable environment

337 produced cod that were faster to recover from a simulated predator attack. However, the results

338 from this study show that exposure to enrichment does not appear to affect anxiety in terms of

339 how often the fish left the floor of the test tank and how they moved in the water column. Even

340 though trout is not constrained to bottom dwelling behaviour in nature (e.g. Galbraith, 1967), the 
341 novel tank diving test was originally designed to assess anxiety in zebrafish (Cachat et al., 2010),

342 and it may be misleading when measuring anxiety in rainbow trout.

344 When any captive reared animal is released into the wild an entirely new world awaits it, and this

345 puts considerable demand on the animal's ability to adjust and adapt. Stocked fish need to learn to

346 recognize new food sources, how to find them and handle them, how to recognize and avoid

347 predators and how to learn and interact appropriately with competitors (Johnsson et al. 2014,

348 Jonsson and Jonsson 2014). Predator avoidance, possibly one of the most important skills to learn

349 in most environments, is partly innate and partly dependant on experience (e.g. Vilhunen and

350 Hirvonen 2003, Patton and Braithwaite 2015) and the ability to learn quickly will provide a

351 survival advantage because there is seldom room for trial and error learning in predator

352 encounters. Other than predation, however, variable and changing environments will naturally

353 present different and varying challenges to animals. An ability to quickly adjust and be able to

354 cope with changing conditions would add a further survival advantage (Näslund and Johnsson

355 2014). The flexibility test results indicate that the longer the fish experienced enrichment, the

356 more flexible and the better they become at adjusting their behaviour to the current

357 circumstances.

\section{5. Conclusion}

360 Together, the results of this study indicate that the duration and recency of exposure to

361 environmental enrichment do influence trout behavioural robustness. The best improvements in

362 terms of developing better learning and memory skills and higher flexibility were found in fish

363 exposed to at least three months of enrichment. However, interestingly, positive effects were also

364 seen in fish that had most recently experienced the enrichment, even though they had had less

365 overall exposure to it. From an applied perspective, the longer hatcheries can provide

366 environmental enrichment the better, but if for some reason long periods of enrichment are not 
367 possible, then providing access to enrichment just before the fish are released might be the best

368 alternative practice.

$370 \quad$ Acknowledgements

371 We thank the Swedish Research Council Formas for funding. We are grateful to Bryan Ferguson,

372 Kate McAndrew, Caroline Marques Maia and Lauren Chaby for their assistance with the trout

373 experiments. This material is based upon work that is supported by the Swedish Research Council

374 Formas annual open call 2012 for applications for mobility starting grants for young researchers

375 [2012-11162-22958-53]. The financial sponsor had no role in study design, collection, analysis

376 and interpretation of data, writing of the manuscript or in the decision to submit the article for

377 publication.

378

379 References

380 Braithwaite, V.A., Salvanes, A.G.V., 2005. Environmental variability in the early rearing

381 environment generates behaviourally flexible cod: implications for rehabilitating wild

382 populations. P. Roy. Soc. B. 272, 1107-1113.

383

384 Braithwaite, V.A., Salvanes, A.G.V., 2010. Aquaculture and restocking: implications for

385 conservation and welfare. Anim. Welfare. 19, 139-149.

386

387 Bredy, T.W., Humpartzoomian, R.A., Cain, D.P., Meaney, M.J., 2003. Partial reversal of the

388 effect of maternal care on cognitive function through environmental enrichment. Neurosci. 118, $389571-576$.

390

391 Brockmark, S., Adriaenssens, S., Johnsson, J. I., 2010. Less is more: density influences the

392 development of behavioural life skills in trout. P. Roy. Soc. B. 277, 3035-3043. 
394 Brown, C., Davidson, T., Laland, K., 2003. Environmental enrichment and prior experience of

395 live prey improve foraging behaviour in hatchery-reared Atlantic salmon. J Fish Biol. 63, 187-

396196

397 Brown, C., Day, R.L., 2002. The future of stock enhancements: lessons for hatchery practice from 398 conservation biology. Fish Fish. 3, 79-94.

400 Brown, C., Laland, K., 2001. Social learning and life skills training for hatchery reared fish. J

$401 \quad$ Fish Biol. 59, 471-493

402

403 Brown, C., Laland, K., Krause, J., 2008. Fish cognition and behavior. John Wiley \& Sons.

405 Cachat, J., Stewart, A., Grossman, L., Gaikwad, S., Kadri, F., Chung, K. M., Wu, N., Wong, K., 406 Roy, S., Suciu, C., Goodspeed, J., Elegante, M., Bartels, B., Elkhayat, S., Tien, D., Tan, J.,

407 Denmark, A., Gilder, T., Kyzar, E., DiLeo, J., Frank, K., Chang, K., Utterback, E., Hart, P.,

408 Kalueff, A.V., 2010. Measuring behavioral and endocrine responses to novelty stress in adult

409 zebrafish. Nature Protoc. 5, 1786-1799.

410

411 Galbraith Jr. M.G., 1967. Size-selective predation on Daphnia by rainbow trout and yellow perch.

412 T. Am. Fish Soc. 96: 1-10.

413

414 Giraldeau, L.-A., Caraco, T., Valone, T.J., 1994. Social foraging: individual learning and cultural 415 transmission of innovations. Behav. Ecol. 5, 35-43.

416

417 Grassie, C., Braithwaite, V. A., Nilsson, J., Nilsen, T. O., Teien, H-C., Handeland, S. O.,

418 Stefansson, S. O., Tronci, V. M. Gorissen, G. Flik \& Ebbesson, L. O. E. (2013) Aluminum 
419 exposure impacts brain plasticity and behavior in Atlantic salmon (Salmo salar) J. Exp. Biol. 216:

$420 \quad 3146-3155$.

421

422 Harburger, L.L., Nzerem, C.K., Frick, K. M., 2007. Single enrichment variables differentially

423 reduce age-related memory decline in female mice. Behav. Neurosci. 121, 679-688.

424

425 Harris, A.P., D’Eath, R.B., Healy, S.D., 2009. Environmental enrichment enhances spatial

426 cognition in rats by reducing thigmotaxis (wall hugging) during testing. Anim. Behav. 77, 1459-

4271464.

428

429 Healy, S.D., 1998. Spatial Representation in Animals. Oxford University Press.

430

431 Heenan, A., Simpson, S.D., Meekan, M.G., Healy, S.D., Braithwaite, V.A., 2009. Restoring

432 depleted coral-reef fish populations through recruitment enhancement: a proof of concept. J. Fish

433 Biol., 75, 1857-1867

434

435 Hilborn, R., 1998. The economic performance of marine stock enhancement projects. B. Mar. Sci.

$436 \quad 62,661-674$

437

438 Hunter, S.A., Bay, M.S., Martin, M.L., Hatfield, J.S., 2002. Behavioral effects of environmental

439 enrichment on harbor seals (Phoca vitulina concolor) and gray seals (Halichoerus grypus). Zoo

$440 \quad$ Biol. 21, 375-387.

441

442 Johnsson J.I., Brockmark, S., Näslund, J., 2014. Environmental effects on behavioral

443 development consequences for fitness of captive-reared fishes in the wild. J. Fish Biol. 85, 1946-

$444 \quad 1971$ 
446 Jonsson, B., Jonsson, N., 2014. Early environment influence later performance in fishes. J. Fish 447 Biol. 85: 151-188.

449 Kempermann, G., Gast, D., Gage, F.H., 2002. Neuroplasticity in old age: Sustained fivefold

450 induction of hippocampal neurogenesis by long-term environmental enrichment. Ann. Neurol. 52, $451 \quad 135-143$.

452

453 Leggio, M.G., Mandolesi, L., Federico, F., Spirito, F., Ricci, B., Gelfo, F., Petrosini L., 2005.

454 Environmental enrichment promotes improved spatial abilities and enhanced dendritic growth in 455 the rat. Behav. Brain Res. 163, 78-90.

457 Maximino, C., de Brito, T.M., da Silva Batista, A.W., Herculano, A.M., Morato, S., Gouveia, A., 458 Jr., 2010. Measuring anxiety in zebrafish: A critical review. Behav. Brain Res. 214, 157-171.

460 McNeil W.J., (1991) Expansion of cultured Pacific salmon into marine ecosystems. Aquac. 98, $461 \quad 173-183$

463 Näslund, J., Aarestrup, K., Thomassen, S.T., Johnsson, J.I. 2012. Early enrichment effects on 464 brain development in hatchery-reared Atlantic salmon (Salmo salar): no evidence for a critical 465 period. Can. J. Fish. Aqua. Sci. 69, 1481-1490.

467 Näslund, J., Johnsson, J., 2014. Environmental enrichment for fish in captive environments: 468 effects of physical structures and substrates. Fish Fish. DOI: 10.1111/faf.12088 469 
470 Näslund, J., Rosengren, M., Del Villar, D., Gansel, L., Norrgård, J. R., Persson, L., Winkowski,

471 J., Kvingedal, E., 2013. Hatchery tank enrichment affects cortisol levels and shelter-seeking in

472 Atlantic salmon (Salmo salar). Can. J. Fish. Aqua. Sci. 70, 585-590.

473

474 Olla, B.L., Davis M.V., Ryer, C.H., 1994. Behavioral deficits in hatchery-reared fish: potential

475 effects on survival following release. Aquac. Fish. Manag. 25, 19-34.

476

477 Patton, B.W., Braithwaite, V.A., 2015. Changing tides: ecological and historical perspectives on

478 fish cognition. Wiley Interdisciplinary Reviews: Cogn. Sci. 6, 159-176.

479

480 Rabin, L.A., 2003. Maintaining behavioural diversity in captivity for conservation: natural

481 behaviour management. Anim. Welfare, 12, 85-94.

482

483 Reader S.M., Laland K.N., 2000. Diffusion of foraging innovation in the guppy. Anim. Behav.

484 60: $175-180$

485

486 Reader, S.M., MacDonald, K., 2003. Environmental variability and primate behavioural

487 flexibility, in: Reader, S.M., Laland K.N. (Eds.), Animal innovation, Oxford University Press, pp.

488 83-116.

489

490 Rodewald, P., Hyvärinen, P., Hirvonen, H., 2011. Wild origin and enriched environment promote

491 foraging rate and learning to forage on natural prey of captive reared Atlantic salmon parr. Ecol.

492 Freshw. Fish, 20, 569-579.

493

494 Salvanes, A.G.V., Braithwaite, V.A., 2006. The need to understand the behaviour of fish reared

495 for mariculture for restocking. ICES J. Mar. Sci. 63, 346-354. 
497 Salvanes, A.G.V., Moberg, O., Braithwaite, V.A., 2007. Effects of early experience on group

498 behaviour in fish. Anim. Behav. 74, 805-811

499

500 Salvanes, A.G.V., Moberg, O., Ebbesson, L.O.E., Nilsen, T.O., Jensen, K.H., Braithwaite, V.A.,

501 2013. Environmental enrichment promotes neural plasticity and cognitive ability in fish. P. R.

502 Soc. B, 280, 20131331.

503

504 Seddon, P.J., Armstrong, D.P., Maloney R. F., 2007. Developing the science of reintroduction

505 biology. Conserv. Biol. 21, 303-312.

506

507 Shier, D.M., Owings, D.H., 2006. Effects of predator training on behavior and post-release

508 survival of captive prairie dogs (Cynomys ludovicianus). Biol. Conserv. 132, 126-135.

509

510 Simon, P., Dupuis, R., Costentin J., 1994. Thigmotaxis as an index of anxiety in mice. Influence

511 of dopaminergic transmissions. Behav. Brain Res.1, 59-64.

512

513 Spence, R., Magurran, A.E., Smith, C., 2011. Spatial cognition in zebrafish: the role of strain and

514 rearing environment. Anim. Cogn. 14, 607-612

515

516 Strand, D.A., Utne-Palm, A.C., Jakobsen, P., Braithwaite, V.A., Jensen, K.H, Salvanes, A.G.V.,

517 2010. Enrichment promotes learning in fish. Mar. Ecol. Prog. Ser. 412, 273-282.

518

519 Urbanek, R.P., Fondow, L.E.A., Zimorski, S.E., Wellington, M.A., Nipper, M.A., 2010. Winter

520 release and management of reintroduced migratory Whooping Cranes Grus Americana. Bird

521 Consev. Int. 20, 43-54. 
523 Vilhunen, S., Hirvonen, H., 2003. Innate antipredator responses of Arctic charr (Salvelinus

524 alpinus) depend on predator species and their diet. Behav. Ecol. Sociobiol. 55, 1-10

525 


\section{Figure captions}

526 Figure 1: Schematic diagram of the side of the test tank and four different wall arrangements for

527 the innovation task. The fish had to find a route from one side of the tank to the other to gain

528 access to a feeder. Each wall was opaque with a single rectangular hole on either the left side

529 (Test 1), and or the right (Test 2). For Wall 3, the fish had to swim down and then up into an

530 opaque tube to reach the hole in the divider. For Wall 4 the set up was the same, except the fish

531 now had to swim down into the tube to reach the hole.

532

533 Figure 2: Schematic diagram of the four-armed maze used for the spatial learning assay. The fish

534 is placed in a transparent cylinder in the middle of the maze before it is allowed to freely move

535 around the maze to find the exit.

537 Figure 3: The predicted probability of a fish in each treatment group finding their way into the

538 alternative half of the test tank and into the feeding area over each of the four flexibility trials

539 shown as a fixed proportion.

540

541 Figure 4: The probability of exiting the maze without making a mistake for each treatment group

542 over 13 maze trials.

543

544 Figure 5: The mean time fish took to exit the maze for each treatment group over all 13 maze 545 trials. 
Table 1. Summary of data and analyses for the novel tank test used to assess anxiety.

\begin{tabular}{|c|c|c|c|}
\hline Screened behaviour & Mean $\pm S E$ & Test used & Statistic result \\
\hline $\begin{array}{l}\text { Time spent motionless on the } \\
\text { bottom of the tank (sec) }\end{array}$ & $\begin{array}{l}E=166 \pm 16.3 \\
L=176 \pm 19.7 \\
3 M=183 \pm 20.8 \\
C=182 \pm 15.8\end{array}$ & $A N O V A$ & $\begin{array}{l}F_{3,72}=0.19 \\
p=0.91\end{array}$ \\
\hline $\begin{array}{l}\text { Number of observations on } \\
\text { middle of tank floor }\end{array}$ & $\begin{array}{l}E=6.3 \pm 1.3 \\
L=6.7 \pm 1.4 \\
3 M=8.5 \pm 1.5 \\
C=5.9 \pm 1.3\end{array}$ & $\begin{array}{l}\text { Kruskal Wallis } \\
\text { test }\end{array}$ & $\begin{array}{l}H=1.86 \\
p=0.60 \\
d f=3\end{array}$ \\
\hline $\begin{array}{l}\text { Number of observations on edges } \\
\text { of tank floor }\end{array}$ & $\begin{array}{l}E=13.7 \pm 1.3 \\
L=13.4 \pm 1.4 \\
3 M=11.5 \pm 1.5 \\
C=14.1 \pm 1.3\end{array}$ & $\begin{array}{l}\text { Kruskal Wallis } \\
\text { test }\end{array}$ & $\begin{array}{l}H=1.86 \\
p=0.60 \\
d f=3\end{array}$ \\
\hline $\begin{array}{l}\text { Number of entries into mid } \\
\text { vertical zone of the tank. }\end{array}$ & $\begin{array}{l}E=2.1 \pm 0.3 \\
L=1.7 \pm 0.4 \\
3 M=3.4 \pm 0.8 \\
C=6 \pm 1.7\end{array}$ & Welch's test & $\begin{array}{l}F_{3,9.15}=2.86 \\
p=0.09\end{array}$ \\
\hline $\begin{array}{l}\text { Proportion of fish leaving the } \\
\text { tank floor }\end{array}$ & $\begin{array}{l}E=43 \% \\
L=35 \% \\
3 M=42 \% \\
C=25 \%\end{array}$ & Chi2-test & Chi2 $=1.1, p=0.77$ \\
\hline
\end{tabular}




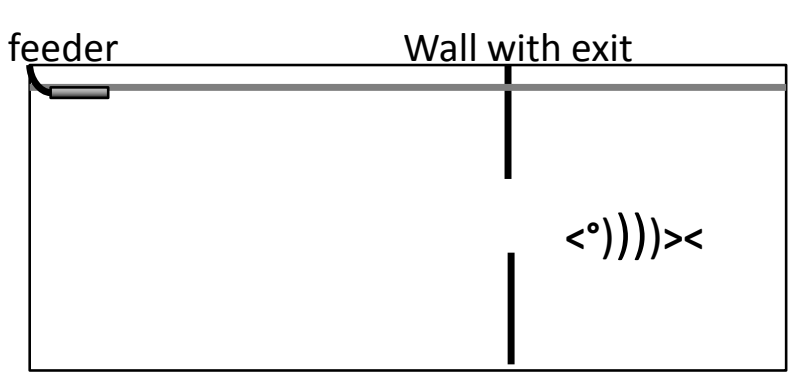

Wall 1

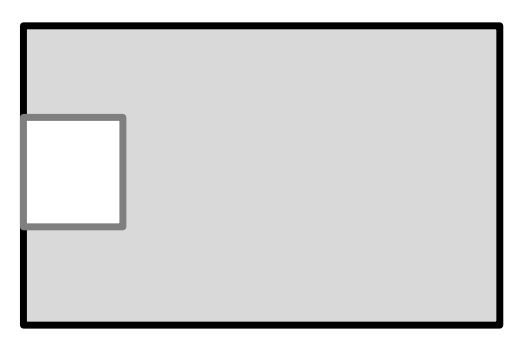

Wall 3
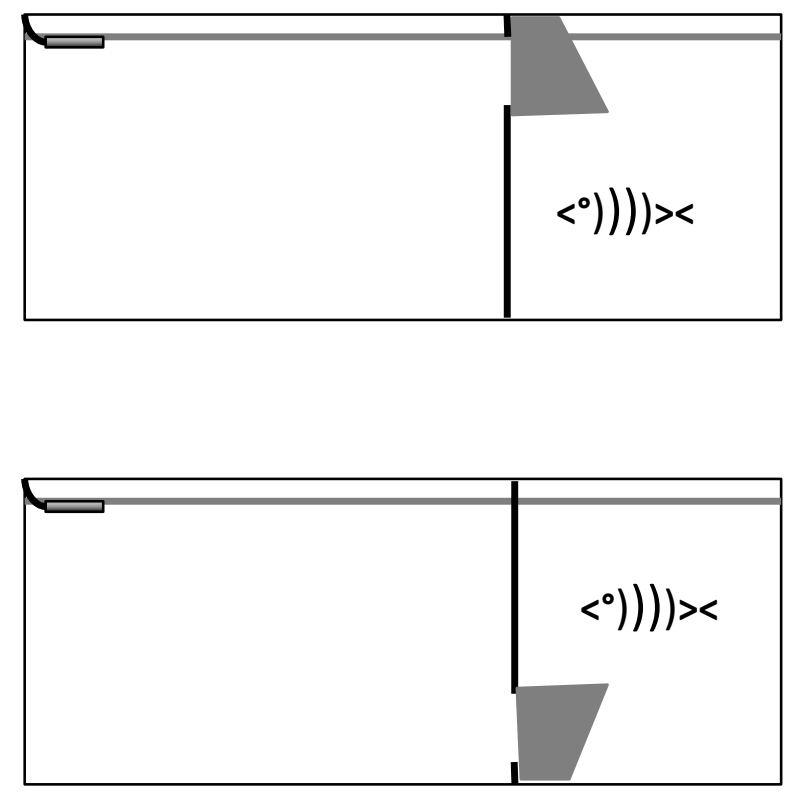

Wall 4

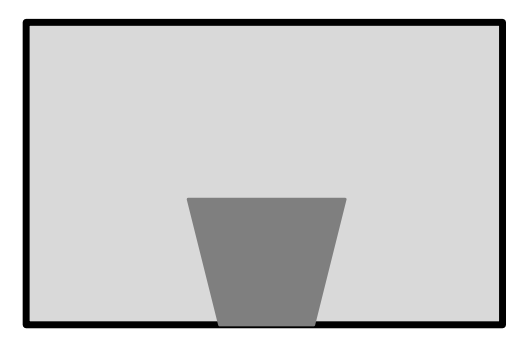

Wall 2

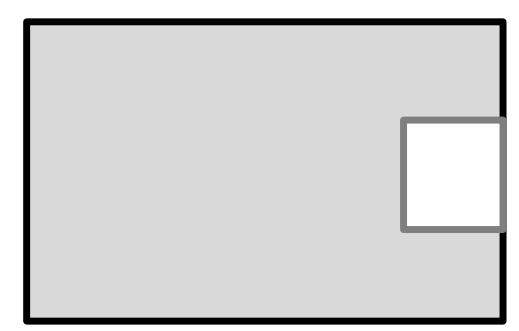




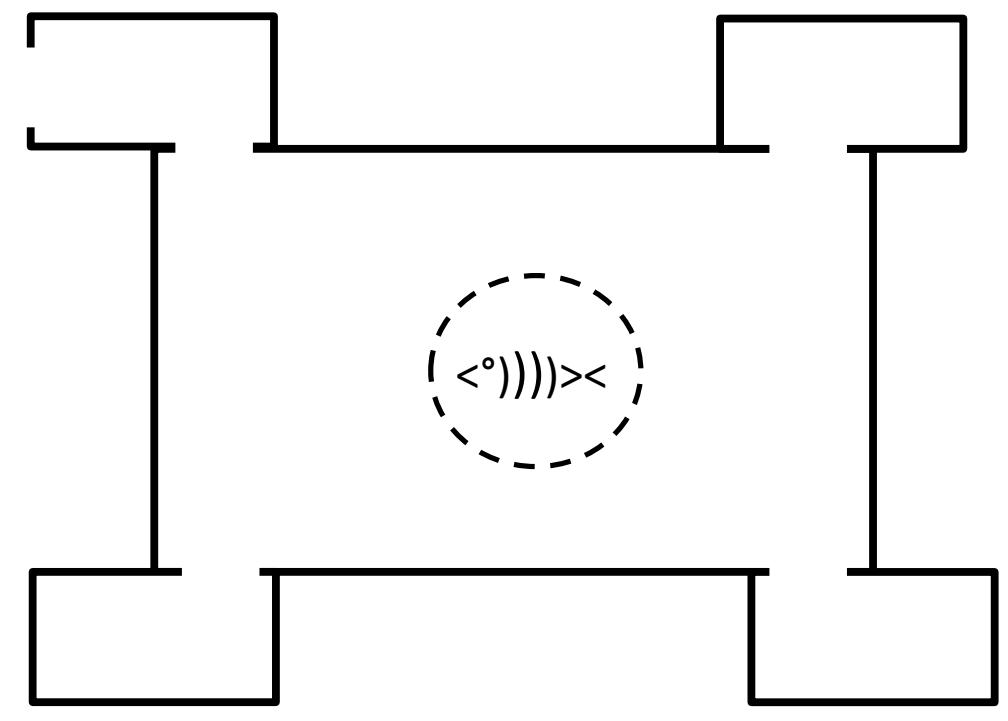




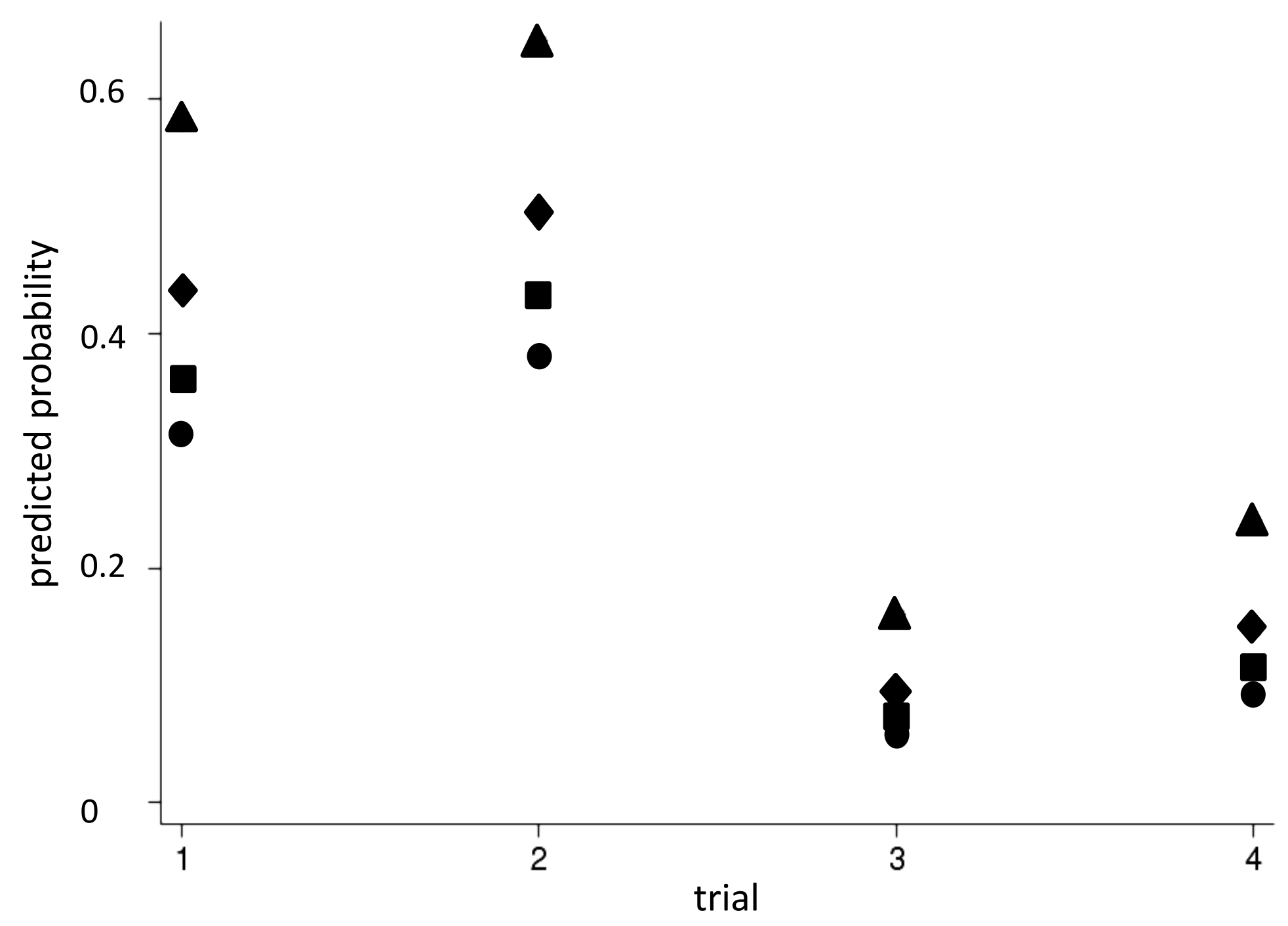

$\Delta$ Full

- Early

- Late

- Control

$\Delta$

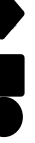

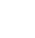




\section{Figure 4}

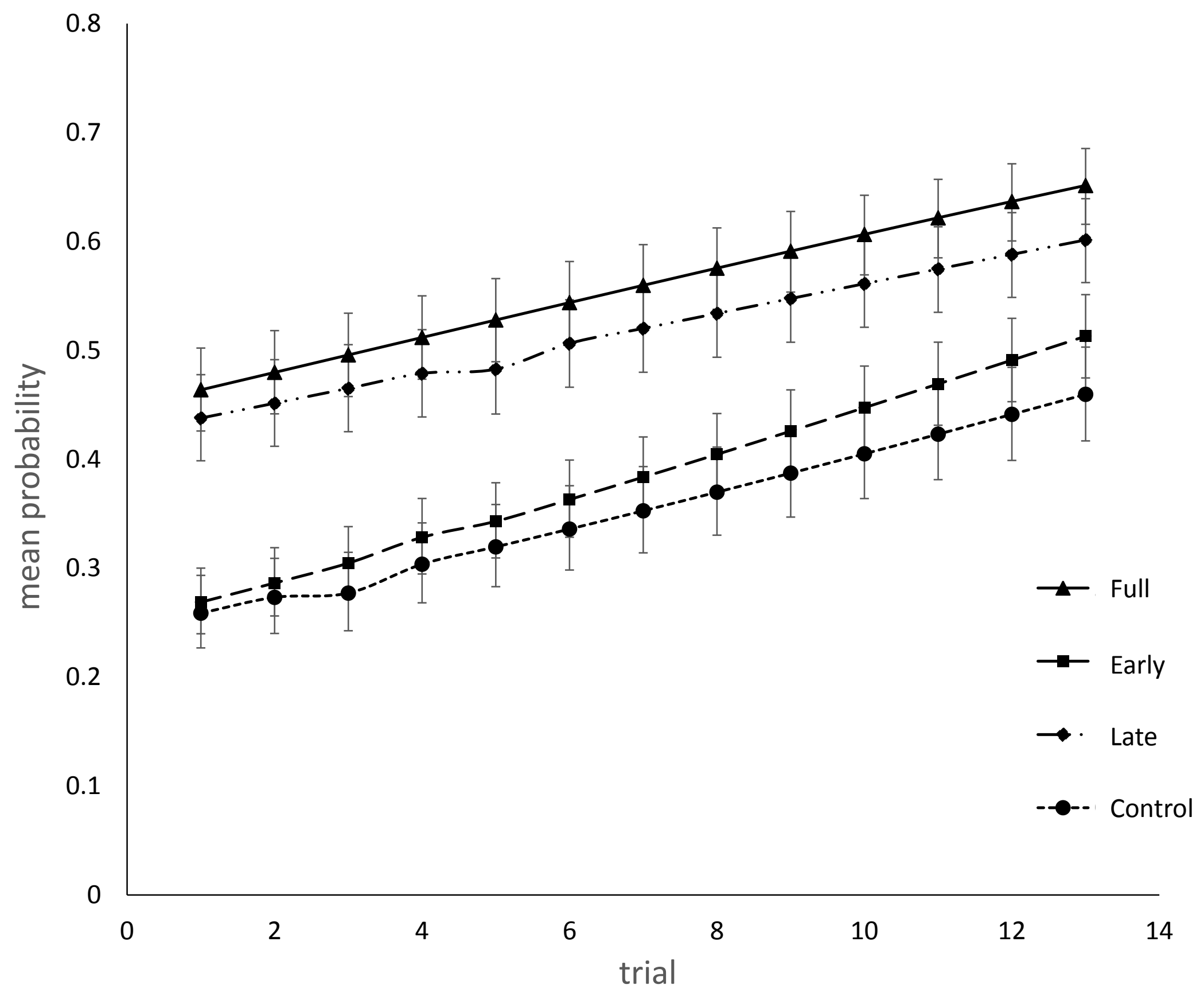




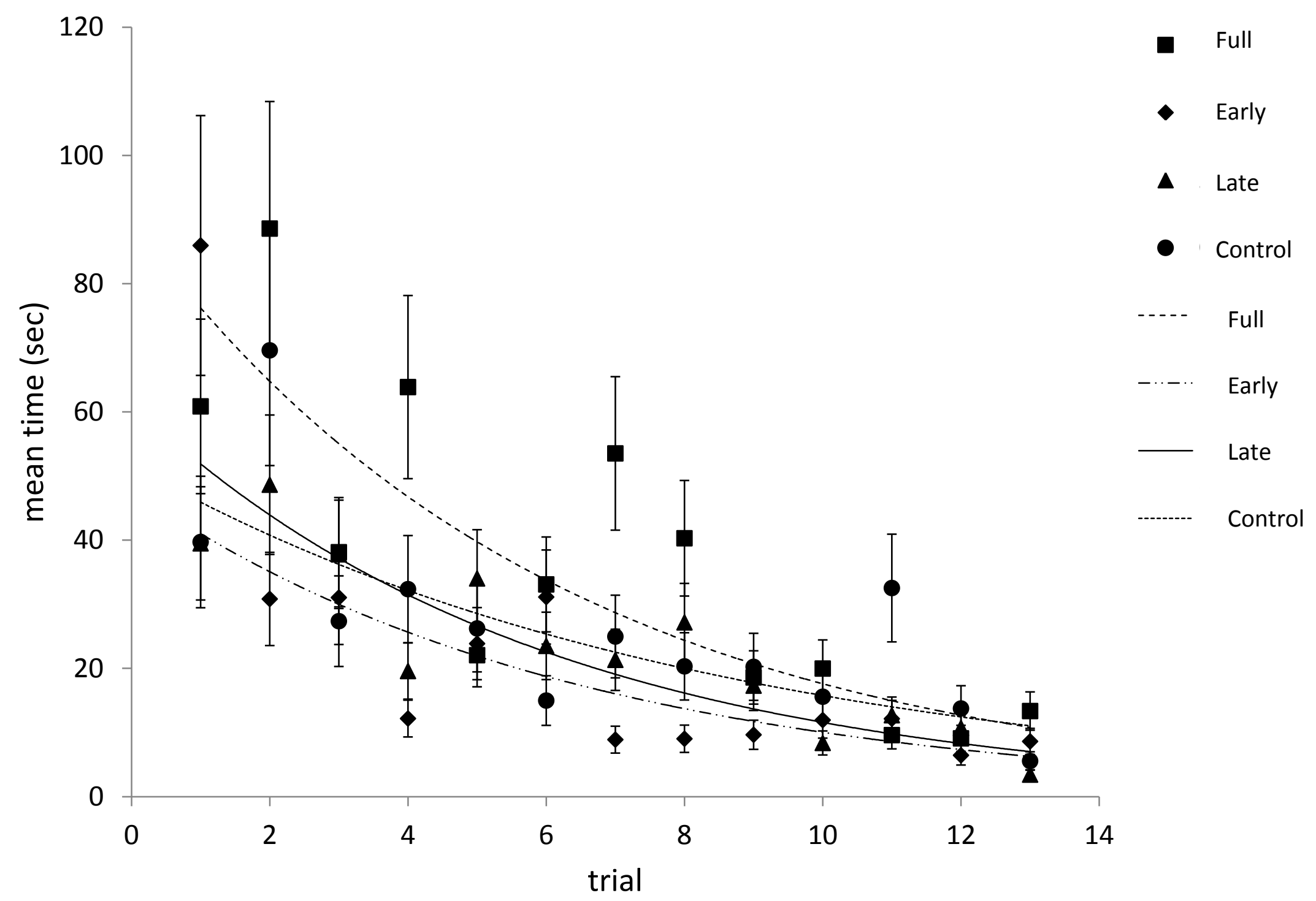

